\title{
Methodological Aspects of On-Farm Monitoring of Cropping Systems Management
}

\author{
Luca Bechini*, Nicola Castoldi \\ Dipartimento di Produzione Vegetale, Università di Milano \\ Via Celoria 2, 20133 Milano, Italy
}

Received: 17 June 2008. Accepted: 26 November 2008.

\begin{abstract}
To conduct agro-environmental assessments at field and farm scale, detailed management data of crop and animal production systems are needed. However, this type of data is only rarely collected by public administrations. In the period 2005-2006, we made an experience of on-farm monitoring of cropping systems management, within a larger project aimed at assessing sustainability of agricultural systems in Italian Parks. In this paper, we describe and discuss the steps taken to carry out periodic face-to-face interviews in farms in the Sud Milano Agricultural Park (northern Italy). The first step was the selection of seven farms, which we identified by applying cluster analysis at a large database describing 733 farms of the Park. After having identified the most relevant agro-environmental issues in the studied area, we established a list of simple but sound indicators to evaluate the effects of agricultural management on the environment. The criteria used to select the indicators were that they should: be calculated on easily available data, not be based on direct measurements, make a synthesis of different aspects of reality, and be easily calculated and understood. The indicators selected evaluate nutrient management, fossil energy use, pesticide toxicity, soil management, and economic performance. Subsequently, we designed a data model to store input data used to calculate the indicators (farm configuration, flows of materials and money through the farm gate, animals and their rations, history of crop cultivation, crop management). The data model that we obtained is relatively complex, but adequate to store and analyse the large amount of data acquired during the two-year project. A questionnaire was developed to fully comply with the indicators selected and the data model. The questionnaire was used to carry out approximately six interviews per farm each year, with an investment of time of 1-2 hours per interview. Appropriate double checks of data collected in the interviews were put in place to ensure a good data quality. The data collected were used for the calculation of several agro-ecological indicators. The results show that nutrient management in maize is not satisfactory due to high surpluses, while meadows have the lowest surplus. The fertilisers and diesel consumption are the most important energy inputs to maize, while their importance is lower for the other crops. Seeds and fertilisers are the main costs for maize and winter cereals, while diesel consumption represents a large part of the economic costs for meadows; pesticides are the principal costs in rice. We concluded by identifying steps for further research.
\end{abstract}

\section{Introduction}

In the past decades, an increasing number of researches have studied the sustainability of agricultural production (Giupponi and Carpani, 2006; Rosnoblet et al., 2006). Due to social and political pressures, issues like nutrient (Sacco et al., 2003) and pesticide use (Bonzini et al., 2006), soil management (Richard et al., 1999), biodiversity (Caporali et al., 2003; Heyer et al., 2003), consumption and production of energy (Ceccon et al., 2002), and greenhouse gases emissions are of great importance nowadays, and the agricul- tural sector is increasingly dealing with them. Researchers and decision makers have addressed these issues by using direct measurements, agro-ecological indicators, or simulation models.

Indicators are traditionally defined as variables supplying information on other variables that are difficult to access (Gras et al., 1989; Bockstaller et al., 1997); moreover, they are suitable entities to be interpreted, providing information to formulate a judgment about the entity under study with respect to a reference pre- 
defined criterion. They are designed to be calculated using data that are accessed relatively easily. Examples of these data in the agricultural sector are databases of public administration, national- or regional-level agricultural statistics (including for example those deriving from censuses), remote-sensed data, and data collected during on-farm surveys (through observation or interview with farm manager). As such, agroecological indicators are suitable for a preliminary but comprehensive evaluation when resources are scarce and a first sustainability assessment is needed. Due to the relatively low data requirement, one advantage of indicators is that they make it possible to conduct a simultaneous assessment of various aspects of sustainability (e.g. energy, nutrients, pesticides, landscape, water quality, and soil management).

Agro-ecological indicators can be calculated at various spatial and temporal scales. For example, the IRENA (OECD, 2002; EEA, 2005) and OECD $(1999,2001)$ agricultural indicators are applied at very large spatial and temporal scales. The IRENA indicators are calculated at the national or sub-national level for 15 European countries, normally on an annual basis. Similarly, the OECD indicators are calculated at national level on a yearly time scale. Other approaches are directed at farm- or field-scale (Vereijken, 1995; Bockstaller and Girardin, 2003). For example, many Authors have calculated the farm-gate nutrient balances (e.g. Fangueiro et al., 2008), to evaluate the nutrient surplus at farm scale, while others have carried out the same type of balance at field level (Sacco et al., 2003), thus providing more insights on nutrients use. Working at crop level, management information needs to be collected at a detailed temporal scale (i.e. month, week). For example, the nitrogen $(\mathrm{N})$ indicator by Bockstaller and Girardin (2003) evaluates the suitability of $\mathrm{N}$ management by integrating detailed information about $\mathrm{N}$ fertilisation (dates, amounts applied, and fertiliser type) with weather and soil data. A disadvantage of working at less detailed scales (i.e. region or nation versus farm or field) is that many extreme phenomena may be averaged out. For example, when a high and a low extreme value are averaged, an intermediate result is produced, which does not show the real situation (that may be critical or dangerous). On the contrary, at more detailed spatial and tem- poral scales this smoothing effect can be reduced (van Beek et al., 2003).

A very general list of data needed to calculate agro-ecological indicators includes information about soils, climate, farm configuration, and crop and livestock management. Of these elements, some can be easily retrieved, while others cannot.

Pedo-climatic information is collected from operational services at the regional level. Structural data describing farm configuration (i.e. the percentage of farm area cultivated with different crops and their allocation to single fields; the number of animals belonging to various age or weight classes; the machinery available on farm) are easily available in databases of public administration (e.g. SIARL, Regione Lombardia, 2008), mainly because these data are needed to fill applications to obtain various subsidies. However, despite its importance for the calculation of farm- and field-level indicators, crop management information (including dates and technical parameters describing each management operation, like tillage, sowing, fertilisation, irrigation, pesticide application, harvest, and post-harvest) is lacking in most situations. For example, no national-level surveys are established in Italy to collect these data, and examples at the regional level are extremely limited.

Therefore, on-farm collection of crop and livestock management information is necessary if management-oriented indicators are to be calculated. Due to the high amount of resources needed for on-farm data collection, monitoring activities can only be carried out on few farms, which need to be carefully selected after analysis of the agricultural sector. On-farm measurements can be carried out automatically using appropriate tools (e.g. Day, 2005) or through farmer's interview.

Within a project aimed at evaluating the sustainability of agricultural activities in protected areas, we have chosen the second option, as this was more convenient for our research unit for economic and organisational reasons. The aim of this paper is to describe and discuss our preliminary experience in selecting and monitoring seven farms in a Park in northern Italy, using periodic interviews to farm managers, by putting particular emphasis on methodological aspects. 


\section{Steps of the sustainability assessment}

The definition of the framework used in this study arisen from the environmental critical issues identified for agricultural systems in this area or in similar areas. Cropping systems are intensively managed in the studied area (Bergamo et al., 2007), with a wide distribution of fodder and cereal crops that in many fields are cultivated in continuous cropping or with a double cropping system (fodder in winter and cereal in summer). The yields are elevated due to the favourable pedo-climatic conditions, the availability of water, and to the intensive use of fertilisers and pesticides, especially in maize and rice. The large use of mineral fertilisers and the numerous agronomic operations increase the use of non-renewable energy. In addition, several intensive livestock farms are present in the Park. Based on the previous considerations and on literature related to similar farming systems, we defined the agro-environmental aspects to be analysed in this study: energy use (e.g. Borin et al., 1997; Ceccon et al., 2002), nutrient balances (e.g. Sacco et al., 2003; Bechini and Castoldi, 2006; Bassanino et al., 2007), soil management (e.g. Marinari et al., 2006), or pesticide fate (e.g. Ferrero et al., 2001; Finizio et al., 2005; Bonzini et al., 2006). Thereafter, indicators were selected to address these aspects. Subsequently, a database and a questionnaire were set-up to collect the necessary data; finally, interviews were made on farms in the area. All the decisions made in this project were linked to: i) the agronomic and environmental aspects identified above, and ii) human and financial resources available to carry out the project. All these steps (Fig. 1) are detailed below.

\subsection{Studied area and selection of farms}

The studied area is the Sud Milano Agricultural Park (PASM; $45^{\circ} \mathrm{N}, 9^{\circ} \mathrm{E}$ ), an agricultural metropolitan Park that embraces the city of Milan (northern Italy). It is located in a plain region and includes 61 municipalities in a densely populated area of 47000 ha, of which 35000 are agricultural (Bechini and Castoldi, 2006). The Park is located in one of the most intensive Italian agricultural production regions. The most important crops are cereal and fodder species; many farms raise livestock (Bergamo et al., 2007).

In the period 1999-2003, a large agricultural information system called SITPAS (Agricultur-

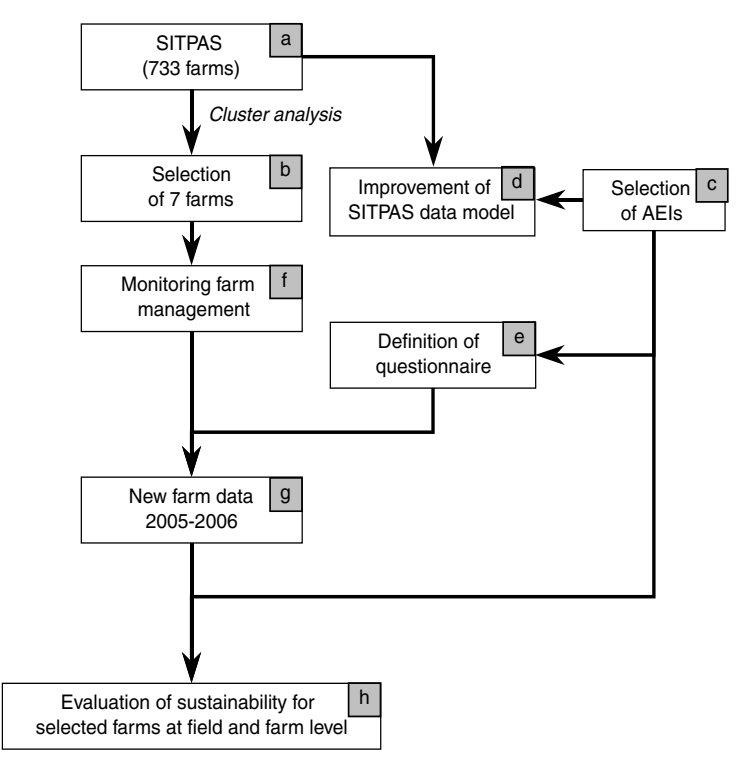

Figure 1. Flow-chart of the sustainability assessment carried out in this study. The SITPAS (Agricultural Information System for the Sud Milano Agricultural Park) database (a) was studied with cluster analysis to select farms (b), where periodic on-farm monitoring was carried out (f). Agro-ecological indicators (AEIs) were selected from literature (c). This made it possible on the one hand to expand the database structure (d) to store additional data required to calculate them, and on the other to define the questionnaire (e) used during the face-to-face interviews. The data obtained $(\mathrm{g})$ were used to carry out the sustainability assessment (h).

al Information System for the Sud Milano Agricultural Park) was developed (Bechini and Zanichelli, 2000; Bergamo et al., 2007) by conducting face-to-face interviews with 733 farm managers, out of a total of 910 . This made it possible to collect and store in the SITPAS detailed information related to cultivated parcels, irrigation sources, mechanisation, crop rotations and management, and livestock management. Crop and animal management information represents the average farmer's practices.

In this work, cluster analysis (CA; Fig. 1) was applied to SITPAS data in order to define groups within which to select the farms to be monitored during the project. Twenty-four descriptors were used in the CA to describe each farm: i) the percentage of farm area cultivated with maize (Zea mays L.), rice (Oryza sativa L.), winter wheat (Triticum aestivum L.), winter barley (Hordeum spp.), soybean [Glycine max (L.) Merr.], Italian ryegrass (Lolium multiflorum 
Lam.), and meadows, ii) livestock densities for dairy, cattle, swine, and poultry, iii) the percentage of farm area under four different irrigation systems used for rice, iv) the percentage of farm area for which land improvement operations, tillage, sowing, pesticide applications, fodder and grain harvests are carried out by contractors, v) the machinery power / farm area ratio, vi) the number of combine harvesters in the farm, and vii) the percentage of farm area under continuous crop. The aggregation method used was the Unweighted Pair Group Method with Arithmetic Mean. The distance between samples (farms) was expressed by the cosine distance. Not all the data were available for all 24 descriptors; therefore, the farms lacking one or more variables were ex- cluded from CA. For that reason, only 496 farms with complete data were selected for CA. One problem when dealing with this type of results is that the number of clusters should be a compromise between two opposite strategies. The first strategy is towards the reduction of the variability within each cluster, which can be achieved by choosing a large number of clusters; in this case, the choice of a farm in the cluster is not difficult because all farms within each cluster are similar. The second strategy is the reduction of the number of clusters, and consequently of the number of farms monitored, in spite of a larger variability within the cluster. We have chosen to identify 18 clusters (Bechini et al., 2005; Castoldi, 2008; Tab. 1), because they well repre-

Table 1. Farm groups identified with cluster analysis, applied on 496 farms described in the Agricultural Information System for the Sud Milano Agricultural Park database.

\begin{tabular}{|c|c|c|c|c|c|c|c|c|c|c|c|c|c|c|c|c|c|c|}
\hline Cluster number & 1 & 10 & 7 & 4 & 6 & 11 & 2 & 8 & 5 & 13 & 12 & 9 & 3 & 17 & 14 & 16 & 15 & 18 \\
\hline Number of farms & 91 & 67 & 54 & 53 & 45 & 41 & 22 & 21 & 19 & 19 & 13 & 12 & 14 & 9 & 6 & 5 & 3 & 2 \\
\hline Average farm area (ha) & 110 & 56 & 61 & 39 & 22 & 41 & 96 & 64 & 53 & 35 & 27 & 26 & 77 & 148 & 7 & 50 & 65 & 48 \\
\hline \multicolumn{19}{|l|}{ CROPS (\% farm area) } \\
\hline maize & 21 & 64 & 70 & 72 & 17 & 50 & 30 & 59 & 28 & 59 & 30 & 24 & 28 & 23 & 75 & 22 & 62 & 23 \\
\hline rice & 67 & 0 & 0 & 0 & 0 & 6 & 49 & 0 & 0 & 0 & 0 & 0 & 63 & 29 & 0 & 52 & 0 & 39 \\
\hline winter wheat & 1 & 1 & 1 & 2 & 0 & 2 & 2 & 2 & 3 & 0 & 1 & 42 & 2 & 3 & 0 & 0 & 0 & 0 \\
\hline barley & 1 & 5 & 2 & 1 & 3 & 5 & 4 & 8 & 3 & 11 & 51 & 9 & 0 & 5 & 0 & 1 & 13 & 0 \\
\hline meadows & 6 & 25 & 17 & 10 & 76 & 28 & 7 & 26 & 11 & 28 & 15 & 11 & 4 & 11 & 13 & 8 & 4 & 32 \\
\hline soybean & 2 & 2 & 1 & 2 & 0 & 3 & 2 & 3 & 39 & 0 & 7 & 2 & 0 & 16 & 0 & 0 & 2 & 5 \\
\hline Italian ryegrass & 2 & 18 & 2 & 0 & 0 & 1 & 2 & 2 & 0 & 3 & 2 & 1 & 3 & 4 & 0 & 3 & 0 & 0 \\
\hline \multicolumn{19}{|c|}{ LIVESTOCK DENSITY (Mg live weight $\mathrm{ha}^{-1}$ ) } \\
\hline dairy & 0.31 & 2.15 & 0.40 & 0.03 & 1.36 & 0.57 & 0.21 & 1.12 & 0.00 & 0.01 & 0.17 & 0.00 & 0.31 & 0.16 & 0.00 & 0.38 & 0.00 & 0.00 \\
\hline cattle & 0.04 & 0.05 & 0.05 & 0.02 & 0.04 & 0.14 & 0.01 & 0.03 & 0.01 & 1.03 & 0.00 & 0.12 & 0.00 & 0.11 & 0.03 & 0.01 & 0.00 & 0.59 \\
\hline swine & 0.03 & 0.01 & 0.07 & 0.00 & 0.01 & 0.11 & 0.13 & 0.39 & 0.03 & 0.01 & 0.23 & 0.18 & 0.13 & 0.00 & 0.00 & 0.00 & 8.26 & 0.00 \\
\hline poultry & 0.00 & 0.00 & 0.00 & 0.00 & 0.00 & 0.00 & 0.00 & 0.00 & 0.00 & 0.00 & 0.00 & 0.00 & 0.00 & 0.00 & 0.00 & 0.00 & 0.00 & 0.14 \\
\hline \multicolumn{19}{|c|}{ RICE IRRIGATION SYSTEMS (\% farm area) } \\
\hline flush & 2 & 0 & 0 & 0 & 0 & 0 & 2 & 0 & 0 & 0 & 0 & 0 & 0 & 0 & 0 & 100 & 0 & 0 \\
\hline delayed-continuous flooding & 24 & 0 & 0 & 0 & 0 & 2 & 20 & 0 & 0 & 0 & 0 & 0 & 4 & 100 & 0 & 0 & 0 & 10 \\
\hline continuous flooding & 73 & 0 & 0 & 0 & 0 & 2 & 39 & 0 & 0 & 0 & 0 & 0 & 13 & 0 & 0 & 0 & 0 & 40 \\
\hline periodic flooding & 1 & 0 & 0 & 0 & 0 & 5 & 4 & 0 & 0 & 0 & 0 & 0 & 83 & 0 & 0 & 0 & 0 & 0 \\
\hline \multicolumn{19}{|c|}{ AGRONOMIC OPERATIONS CARRIED OUT BY CONTRACTORS ( $\%$ of farm area treated) } \\
\hline land improvement & 0 & 2 & 0 & 0 & 0 & 5 & 100 & 0 & 0 & 0 & 0 & 0 & 7 & 0 & 0 & 0 & 33 & 0 \\
\hline tillage & 0 & 0 & 0 & 0 & 1 & 29 & 0 & 1 & 10 & 1 & 0 & 0 & 1 & 0 & 0 & 10 & 33 & 0 \\
\hline sowing & 1 & 1 & 0 & 0 & 0 & 90 & 0 & 0 & 13 & 3 & 0 & 0 & 0 & 0 & 0 & 0 & 33 & 0 \\
\hline pesticide application & 0 & 5 & 0 & 0 & 0 & 69 & 0 & 100 & 13 & 5 & 0 & 8 & 0 & 7 & 0 & 0 & 33 & 0 \\
\hline fodder harvest & 15 & 55 & 2 & 0 & 7 & 14 & 15 & 39 & 3 & 16 & 0 & 0 & 5 & 6 & 0 & 23 & 33 & 0 \\
\hline grain harvest & 24 & 70 & 1 & 97 & 31 & 90 & 49 & 81 & 86 & 47 & 62 & 50 & 15 & 95 & 67 & 60 & 90 & 0 \\
\hline $\begin{array}{l}\text { MACHINERY POWER / } \\
\text { FARM AREA }(\mathrm{kW} \mathrm{ha-1)}\end{array}$ & 6.6 & 8.2 & 7.6 & 7.5 & 11.5 & 6 & 5.4 & 7.4 & 5.7 & 9.6 & 10.6 & 7.7 & 6.1 & 4.3 & 66.8 & 6.4 & 4.1 & 6.3 \\
\hline $\begin{array}{l}\text { COMBINE HARVESTERS } \\
\text { (number farm }{ }^{-1} \text { ) }\end{array}$ & 0.9 & 0.0 & 0.4 & 0.0 & 0.0 & 0.0 & 0.4 & 0.0 & 0.1 & 0.3 & 0.0 & 0.3 & 0.9 & 0.0 & 0.8 & 0.2 & 0.0 & 0.5 \\
\hline $\begin{array}{l}\text { CONTINUOUS CROP } \\
(\% \text { farm area })\end{array}$ & 50.8 & 46.0 & 55.0 & 60.6 & 91.4 & 60.3 & 54.0 & 60.7 & 24.2 & 42.4 & 52.2 & 49.5 & 43.0 & 18.6 & 100.0 & 43.2 & 38.5 & 32.1 \\
\hline
\end{tabular}


sented the different types of farming systems in the Park; when we tried to reduce the number of clusters, these contained excessively heterogeneous farm types (data not shown).

The largest farm types (with at least 19 farms per cluster, including $87 \%$ of farms and covering $88 \%$ of the area) that we could define are (Tab. 1): five clusters of dairy farms, eventually with pigs and cattle (clusters 6, 7, 8,10, and 11); one cluster of cattle farms (cluster 13); two clusters of specialised rice farms (clusters 1 and 2); one cluster of pure maize farms (cluster 4); and one cluster of farms producing grain commodities (cereals and soybean; cluster 5).

Despite that each cluster has average values of the descriptors that make it apparently different from the others, when we inspect the variability within the clusters we find that they are rather heterogeneous: for example, the standard deviation of percentage maize in cluster 4 is $28 \%$ (to be compared with the average of $72 \%$ ). Similar examples can be found for most distinctive properties of clusters, i.e. dairy livestock density for clusters $6,7,8,10$, and 11 (standard deviations from 0.73 to $1.80 \mathrm{t} \mathrm{ha}^{-1}$ ), standard deviation of cattle density of $0.73 \mathrm{tha}^{-1}$ for cluster 13 , and standard deviation of percentage rice of 28 and $42 \%$ for clusters 1 and 2, respectively. These results underline the difficulty of depicting agricultural systems using few monitored farms.

Once the clusters have been identified, we selected candidate farms within the largest clusters, i.e. the clusters containing many farms. Within each cluster, farms were selected by combining two criteria: first, each farm descriptor needed to be relatively similar to the average of the descriptor calculated for all the farms within that cluster; moreover, farmers should have been described as "technically skilled and willing to collaborate" in the SITPAS database. At the end of the selection procedure, we verified that, for each farm, the majority of the descriptors was included in the range mean \pm standard deviation of the cluster. During preliminary meetings with these candidate farmers we clarified the objective of the project and our data requirements. After that, some farmers were excluded, either because they were not interested in the project, or because they were unavailable, or due to the bad quality of the information that they could provide. We finally se- lected two dairy farms (one intensive and one extensive), one cattle farm, and two rice farms (one specialised, and one with maize and other grain crops). Even if the cluster of pig farms (cluster 15) was extremely small, several pig farms were clearly present in other clusters (e.g. cluster 8 , together with dairy animals). Consequently, and due to the high importance of pig farming for environmental reasons, we decided to include two pig farms, one intensive from cluster 15 and one extensive from cluster 7. We consider that the choice of farms is satisfactory, as they cover all the main crop and livestock types identified with CA.

The farmers involved collaborated without receiving economic compensation. This factor contributed to reduce farmers' availability during the intensive spring-summer season. In some occasions the farmers were too busy and in these cases the interviews were shifted or concentrated. For future project, a contract with farmers and a corresponding payment is suggested to guarantee their collaboration in all periods.

\subsection{Definition of the indicator framework}

According to the agro-environmental issues identified for the studied area, a set of indicators of cropping systems management was selected from literature (Vereijken, 1995; Parris, 1998; Biermann et al., 1999; Bockstaller and Girardin, 2003; OECD, 2005; Castoldi and Bechini, 2006; Castoldi et al., 2007b; Migliorini and Vazzana, 2007; Castoldi, 2008; Meul et al., 2008). For this purpose, we have defined five indicator classes concerning the most important aspects of economic and environmental sustainability: economic performance, use of energy and nutrients, pesticide toxicity, and soil management. These classes are similar to those found in the literature on farm management analysis (Vereijken, 1995; Bockstaller and Girardin, 2003) and policy analysis (OECD, 2001; EEA, 2005).

The criteria applied in the selection of indicators were (Castoldi and Bechini, 2006): i) data availability (inputs for indicator calculation should be derived from farm characteristics, from farmer, or from existing agricultural databases); ii) synthesis (the indicator should integrate different aspects of reality, providing a numerical value characterised by a good compro- 
mise between the description of the processes and their simplification into a single value); iii) simplicity (the indicator needs to be easily calculated and interpreted). We therefore excluded the indicators constituted by direct measures on soils, waters or crops (e.g. ANPA, 2000).

As a result of the literature review, in the economic class we have selected: gross income (GI), variable costs (VC: sum of the costs for fuels, lubricants, pesticides, fertilisers, and seeds), economic balance (GI-VC), and efficiency (GI/VC). Nutrient management was described by NPK soil surface balances (Parris, 1998). The energy indicators selected are: energy input (EI: sum of energy in the fuels, lubricants, pesticides, fertilisers, seeds, and machinery), energy output (EO: energy content of above-ground biomass), energy balance (EO$\mathrm{EI}$ ), and efficiency (EO/EI) (Biermann et al., 1999; Ceccon et al., 2002). Potential environmental fate of pesticides in air, soil, and groundwater was described using environmental exposure-based pesticide indicators (Verejiken, 1995). Their toxicity for non-target organisms was evaluated with the Load Index (OECD, 2005) that is the ratio between the application rate and the acute toxicity of active ingredient (a.i.), calculated separately for rats, birds, earthworms, bees, fish, crustaceans, and algae. Soil management was described with the: crop sequence indicator (Bockstaller and Girardin, 2003), that evaluates the average goodness of each previous-successive crop combination; the soil cover index (Vereijken, 1995), that is the average percentage of soil cover by crops in one year; and the soil organic carbon indicator (Bockstaller and Girardin, 2003), evaluating if the management on a specific soil tends to accumulate or deplete soil organic carbon.

Not all environmental issues are included in our framework: some are not interesting in the studied area (e.g. soil erosion, as the area is flat; Acutis et al., 1996), while in other cases the necessary data were not obtainable on farm (e.g. water quality, use of irrigation water, greenhouse gas emissions).

It should be emphasized that the selected indicators describe the state of farm management. In order to estimate the impact, in most cases direct measurements should be carried out, or dynamic simulation models should be applied (e.g. actual pesticide fate is properly addressed only with model-based indicators like EPRIP; Padovani et al., 2004). In addition, when the objective is the improvement of cropping systems sustainability, models are probably the only solution.

\subsection{Database design and implementation, and da- ta analysis}

The calculation of a single indicator is relatively simple, if it is carried out for one situation only (e.g. one crop, or one rotation, or one farm). However, the need to automatically compute many indicators for many crops in many farms requires data management procedures that can only be achieved using a database. Therefore, to provide a repository for our newly collected data, we decided to improve the SITPAS data model following indicator selection. The resulting data model, developed with the entity-relationship framework (Garcia-Molina et al., 2002), was implemented with the relational database management system Microsoft Access. More information on the database is contained in Bechini and Castoldi (2006). The database is consistent with the questionnaire used for the interviews.

In the data model, the farm has one or more fields; for each field, the history of cultivation is recorded, by indicating the list of crops that were cultivated on that field. Each field is georeferenced in a GIS. For each crop, agronomic operations can be recorded (tillage, sowing, fertilisation, irrigation, herbicide, fungicide and insecticide application, harvest, and drying). For each operation, several variables can be specified: the type of operation, the date on which the operation was carried out, the percentage of crop area treated (less than or equal to $100 \%$ ), the depth of tillage. For operations involving the application of one or more products (fertilisers or pesticides), the type, amount and price of product(s) applied are indicated. For harvest operations, the yield(s) and the fate of harvested product(s) and residues can be specified (sold with indication of the price -, recycled within the farm - for example as animal feed -, re-incorporated into the soil). For prices, it is always possible to indicate what the source of the information was (farmer, Milan Stock Exchange quotations, dealers).

For animal production, the data model specifies that a farm may have one or more animal 
breeds. Each of them is composed of various animal groups (distinguished by age or weight). For each group the ration is specified by listing the daily amount of feed received per capita. The number of animal heads belonging to each group and the ration are dynamic data that can be updated. At the farm level, we store flows of materials and money through the farm gate.

Other entities are used to store various literature data needed for the calculation of indicators: nutrient excretion of animals, humification coefficients of organic amendments, ecotoxicological parameters of pesticides, harvest indexes, shoot:root ratios, crop nutrient concentrations, specific fuel and lubricant consumption for crop operations, energy content of fertilisers, pesticides, seeds, fuels, lubricants, crop products, and residues. For each product applied, the detailed composition is available in the database (e.g. N, P, and K contents of fertilisers, a.i. of pesticides), through a list that can be expanded. For pesticides in particular, eight toxicological and physical characteristics for each a.i. were recorded (Tomlin, 2003; Footprint Pesticide Properties Database, 2008; AGRITOX, 2008).

Despite the simplicity of the indicators, the data model is rather complex, because it is made of 91 entities and 53 domains (i.e. closed lists containing qualitative information, used to avoid typing errors and to ensure data consistency). This complexity arises from the fact that we deal with two different spatial scales (farm and fields), that we want to remember the entire cultivation history of each field and the ration of each animal group, and that we decided to assess different aspects of agricultural sustainability. Because the data to be stored describe farm structure, crop operations and livestock management in abstract terms, the data model that we used was rather general. Therefore, it can be expanded to store more variables without changing too much the general design and can be easily adapted to be used in other agricultural contexts (e.g. horticulture, arboriculture). For example, if an application of the database is envisaged for protected cultivation systems, it would be simple to add new active ingredients and new types of agronomic operations, because this would not require to change the architecture of the database. We believe that the use of a relational database for this type of projects is a mandatory requirement due to the large amount of data to be stored and processed, and to the complexity of the relationships among the objects studied (Bechini and Castoldi, 2006). Although a spreadsheet appears to be a simpler solution at a glance, it is not productive in the medium and long term. The use of a database makes it possible to store simple data in tables that can be used for the calculation of more than one indicator, avoiding duplication of information and reducing the possibility of errors in data typing.

However, a consequence of the use of a database is that data management is very complex and many queries are necessary to obtain a single indicator. Another complication of this data model is that the total number of records stored in the database for a monitoring period of two years on seven farms is relevant. Finally, it should be noted that the requirement of a complex database to deal with indicators takes off some of the simplicity that indicators are expected to bring into agro-ecological research.

\subsection{Set-up of the questionnaire, interviews and data quality check}

To collect the data needed for indicator calculation, we decided to carry out face-to-face interviews, as a solution to collect management information that would be difficult to obtain otherwise. To carry out interviews, we developed a questionnaire that is completely consistent with the indicators selected and the database used.

The questionnaire is composed by two parts. The first part contains static data about the structure of the farm (general information about farm manager, machinery and buildings, field size and shape, vegetation of field boundaries). This part was compiled only in the first interview, considering that during the monitoring period these data did not change substantially. The second part, compiled during each interview, contains dynamic data at field level: tillage operations, sowing (date, dose, cost, variety, and sowing type), fertiliser application (date, dose, nutrient concentration, and cost), pesticide application (date, dose, a.i. concentration, and cost), irrigation (date and irrigation type; farmers were not aware of the quality and quantity of water applied), harvest (date, yield, humidity, typology of the product, and selling price). Other information regarding livestock management (number and type of animals pre- 
sent in the farm, and daily ration), input and output flows through the farm gate (fertilisers, pesticides, fuels, lubricants, electricity, manure, feeds, animals, and animal products, imported or exported from farm) were collected once or twice a year. As for the database, also the questionnaire is flexible and can be easily extended if it has to be applied to other contexts (e.g. by expanding the list of crop operations or of products applied).

The data were collected by face-to-face interviews with farm managers, carried out every two or three months, depending on the season and therefore on time availability of the farm manager. On average two or three interviews per farm had to be postponed each year for different reasons. The main reason was the need to conclude important crop operations (sowings, irrigations, and harvests in particular), while in other occasions the farm managers were busy with other activities (e.g. fairs) or with unforeseen events (problems with machinery, animal health, administrative controls).

The compilation of the questionnaire was rather time consuming, in particular for the first part. The first interview required about 3-4 hours (that in some cases were split over two different days), while each of the other interviews required between one and two hours. We calculated that the time required for the interviews was approximately 8-12 hours farm ${ }^{-1} \mathrm{yr}^{-1}$, corresponding to 4-21 minutes $\mathrm{ha}^{-1} \mathrm{yr}^{-1}$. This large range was due to field size, number of crops cultivated and variability of management for each crop type in the same farm. For example, one of the farmers adopted an homogeneous management for maize over different farm fields, while a rice grower provided detailed differences among fields. The time needed for the transfer from office to farm and vice versa was not negligible, as it was in some cases of the same importance of the time spent for the interview (the farthest farm was at $50 \mathrm{~km}$ distance). To reduce the time spent on farm, the data were sketched on paper during the interview. Later in the office, data were checked and input into a graphical user interface built around the relational database. Sometimes a unique farm manager did not exist and conflicting information was provided by two or more managers. Therefore, the identification of a single farm manager, with a clear and ex- haustive knowledge of the entire farm, is suggested in order to reduce the uncertainty and the errors in data collection.

Some farmers tried to compile the questionnaire by themselves, but some misunderstandings in the data requirements and errors in filling the tables occurred; therefore, an accurate check and a subsequent interview with the farmer were necessary in order to correct the errors and to clarify the uncertainties. Therefore, this strategy increased the time spent by farmers and researchers for data collection. Another problem that may occur during data collection is that farmers may forget to declare some crop operations or other information. The lack of some data may not appear immediately during the interviews. To solve this problem, i) we double-checked collected data (e.g. by comparing the declared dose of products applied with the bills), and ii) we followed the strategy described by Giupponi (2002), who defined a standard set of crop management operations, which was then used as a template during the interview. The agronomic background of the person conducting the interviews has to be good in order to avoid registering inconsistent or contradictory data, and to reduce the time needed for quality check and errors correction.

\subsection{Example of calculated agro-ecological and economic indicators}

We provide some examples of the results that can be obtained with the methodology described above. The nitrogen soil surface balance, reported in Figure 2, shows that maize has the highest surpluses, meadows have the lowest, and rice, barley and wheat are in an intermediate position. Maize is the crop where too much $\mathrm{N}$ is applied, mainly due to the use of organic fertilisers. The variability within each crop type is elevated.

The direct and indirect energy inputs are presented in Figure 3: fertilisers are the most important energy input to maize, due to the intensive use of inorganic fertilisers and animal manures. Their importance is lower in other crops, but they are always the first- or secondranked input. Rice is the only crop where the energy expenditure for pesticides is relevant $(11 \%)$. Diesel consumption is very important for the cultivation of meadows, due to frequent hay-making and irrigation operations. 


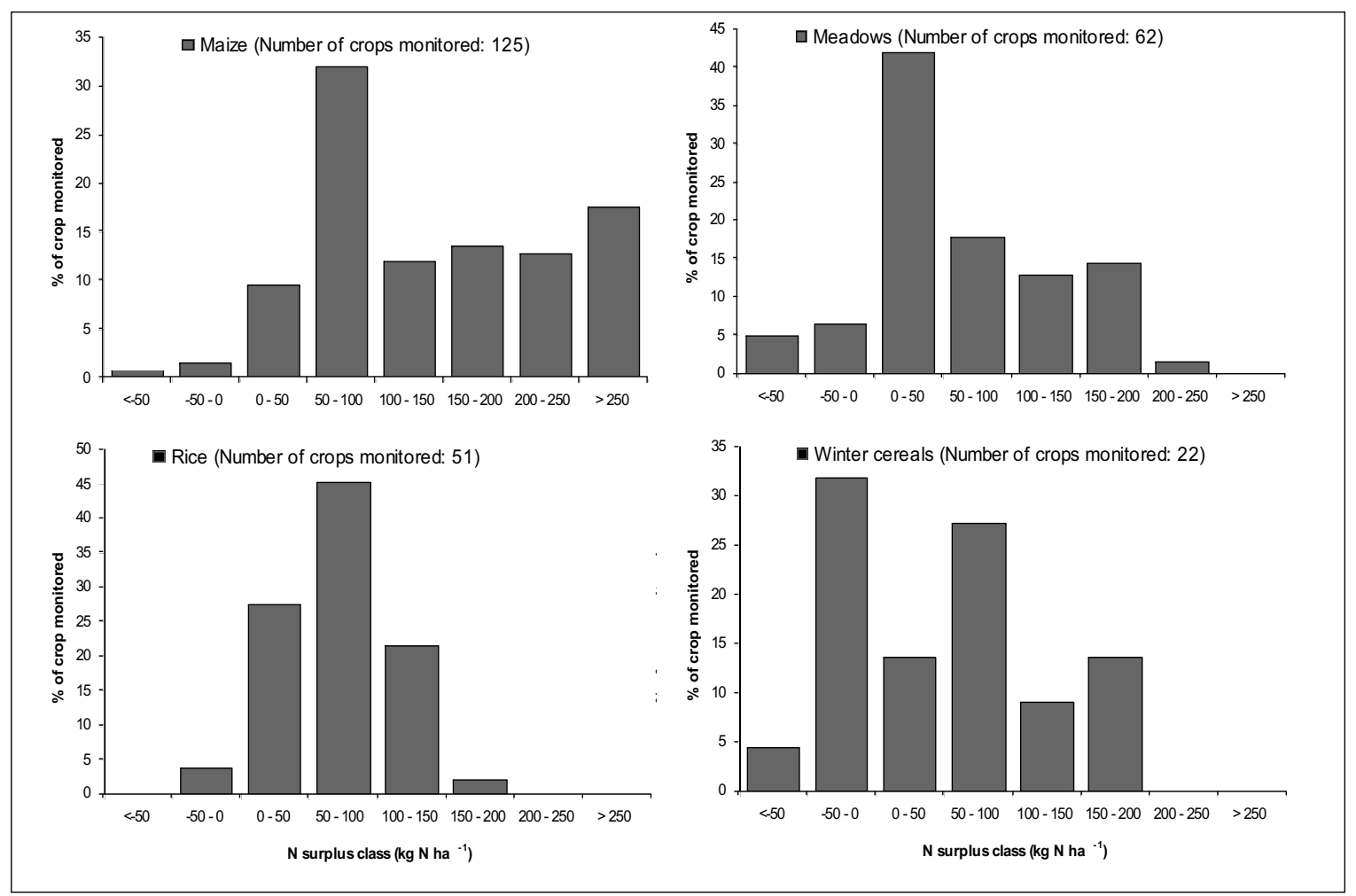

Figure 2. Statistical distribution of the nitrogen soil surface balance calculated for maize, meadows, rice and winter cereals (winter wheat and barley) on seven farms in the Sud Milano Agricultural Park during two years (2005-2006).

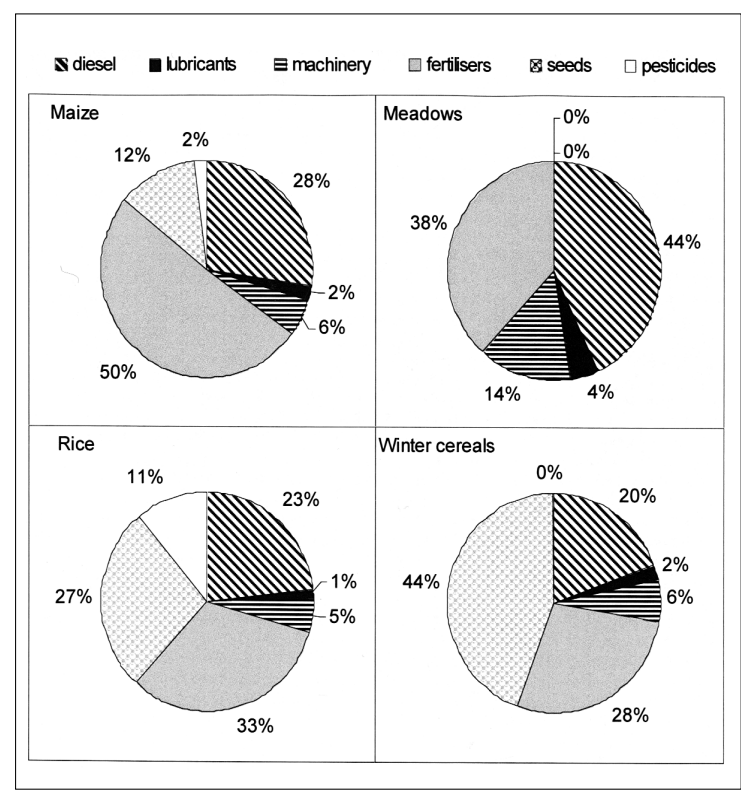

Figure 3. Percentage contribution of direct (diesel and lubricants) and indirect (machinery, fertilisers, seeds, and pesticides) energy costs to total energy inputs for maize, meadows, rice, and winter cereals (winter wheat and barley) on seven farms in the Sud Milano Agricultural Park during two years (2005-2006).
The economic partitioning of costs (Fig. 4) is completely different compared to energy inputs. Seeds and fertilisers are the most important costs for maize and winter cereals. Diesel consumption makes up large part of the economic costs for meadows. In rice, pesticides are the largest cost, due to the high use of herbicides and fungicides.

The application of indicators for the monitoring of cropping systems management provided a synthetic evaluation of crop performance, simultaneously for different environmental and economic aspects. The application of this framework made it possible to distinguish different crops (e.g. rice versus maize; Figg. 2, 3, and 4), and different management practices for the same crop (e.g. maize in dairy intensive versus maize in rice-cereal farms; Castoldi, 2008), highlighting the potential impact and virtuosity of each cultivation system.

The application of this framework to a larger representative set of farms could provide the necessary information for the assessment of agricultural systems in the PASM, giving to the 


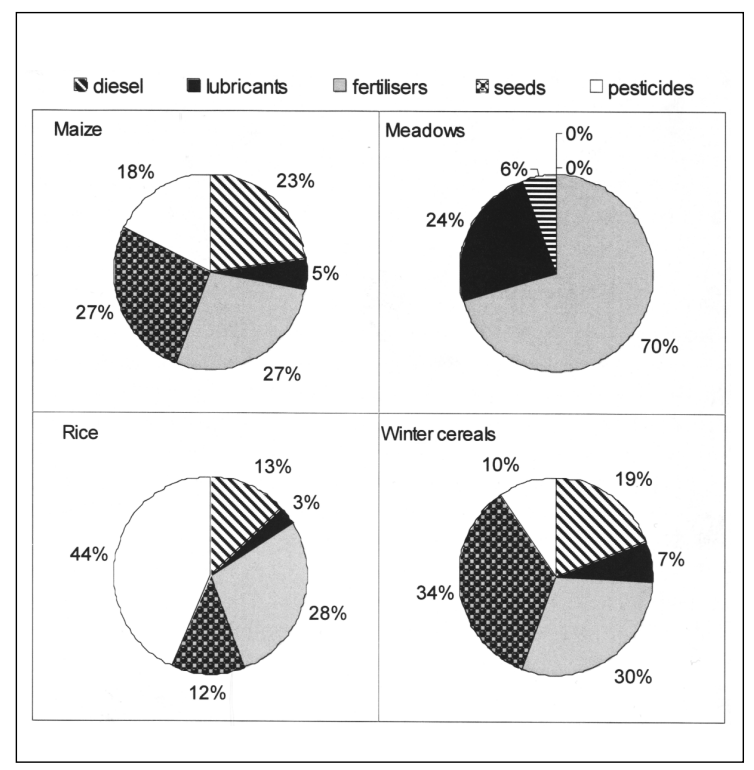

Figure 4. Percentage contribution of diesel, lubricants, fertilisers, seeds, and pesticides to the economic costs for maize, meadows, rice, and winter cereals (winter wheat and barley) on seven farms in the Sud Milano Agricultural Park during two years (2005-2006).

Park and to other policy makers the tools and knowledge needed to set policies, guidelines, and priorities.

The intrinsic uncertainty of this type of analyses might reduce the effectiveness of the assessment. A quantitative evaluation of uncertainty in the results (e.g. Castoldi et al., 2008) is a mandatory step for the correct application of indicators and will be increasingly needed in future research.

Moreover, further research should be focussed on the aggregation of indicator values into a global index. Examples of a preliminary approach to provide an aggregated judgment on the cropping systems monitored can be found in Castoldi et al. (2007a) and Bechini and Castoldi (2008).

\section{Conclusions}

Within a project aimed at assessing agricultural sustainability from the environmental and economic point of view, we have made a two-year experience of on-farm collection of management data through face-to-face interviews, which we used to calculate indicators.
Our experience shows that to collect good quality data on selected farms, the selection of a small number of collaborative farmers is crucial. Even if the farms monitored were not many, the within- and between-farm variability was very high. Moreover, dealing with few farmers gave us the possibility of establishing a good relationship with all of them, and to make periodical interviews each year.

We chose a simple but sound framework, based on indicators that are easily calculated and interpreted. We designed and implemented a relational data model tailored to the indicators selected. We avoided using a spreadsheet to store and analyse our data, as it would have been too complicated for a project of this size (131 fields monitored in two years).

We set up a questionnaire to conduct faceto-face interviews with farmers. The questionnaire was completely fitting with both the indicators and the database, so that all the data needed for the calculation were acquired and stored, and no useless data were collected. The time spent for the interviews and data storage was relevant. Therefore, it is suggested that further projects investigate the possibility of data collection using automatic sensor for yield data and fertilisers and pesticides applied.

\section{Acknowledgements}

The methodology described here was developed during the PRIN 2004 project "Un'agricoltura per le aree protette" ("Agriculture for protected areas": http://www. unirc.it/agripark/), coordinated by Prof. Maurizio Borin, and funded by the Italian Ministry for University and Research. We are very grateful to all the farmers interviewed during this research.

We also thank two anonymous reviewers for providing useful comments.

\section{References}

Acutis M., Argenti G., Bersani L., Bulletta P., Caredda S., Cavallero A., Giordani C., Grignani C., Pardini A., Porqueddu C., Reyneri A., Roggero P.P., Sulas L., Talamucci P., Zanchi C. 1996. Effetti di tipologie di suolo e colture foraggere sulle perdite per ruscellamento di azoto, fosforo e potassio in differenti areali italiani. Riv. Agron., 3:329-338.

AGRITOX. 2008. Base de données sur les substances actives phytopharmaceutiques. [Online]. Available at: http://www.dive.afssa.fr/agritox/php/fiches.php; last checked on 20 November 2008. 
ANPA (Agenzia Nazionale per la Protezione dell'Ambiente) 2000. Sviluppo di indicatori per il suolo e i siti contaminati. RTI CTN_SSC1/2000.

Bassanino M., Grignani C., Sacco D., Allisiardi E. 2007. Nitrogen balances at the crop and farm-gate scale in livestock farms in Italy. Agric. Ecosyst. Environ., 122:282-294.

Bechini L., Castoldi N. 2006. Calculating the soil surface nitrogen balance at regional scale: example application and critical evaluation of tools and data. Ital. J. Agron. / Riv. Agron., 1:665-676.

Bechini L., Castoldi N. 2008. Assessment of Crop Management Using Agro-Ecological and Economic Indicators. In: Rossi Pisa P. (ed.): Multi-functional agriculture; agriculture as a resource for energy and environmental preservation. Proceedings $10^{\text {th }}$ ESA Congress, 15-19 September 2008, Bologna, Italy, 297-298.

Bechini L., Castoldi N., Bergamo D., Penati M., Zanichelli I., Maggiore T. 2005. Analisi e aggiornamento di un sistema informativo territoriale per l'agricoltura: il caso del Parco Agricolo Sud Milano. In: Giuliani M.M., Gatta G. (eds.): Ricerca ed innovazione per le produzioni vegetali e la gestione delle risorse agro-ambientali. Proceedings $36^{\text {th }}$ Italian Society for Agronomy Congress, 20-22 September 2005, Foggia, Italy, 398-399.

Bechini L., Zanichelli I. 2000. A database for agricultural activities at farm scale for a metropolitan agricultural park. In: Christen O., Ordon F. (eds.): Proc. of $3^{\text {rd }}$ International Crop Science Congress, Hamburg, Germany, 17-22 August, 124.

Bergamo D., Penati M., Zanichelli I. 2007. Sistema Informativo Territoriale del Parco Agricolo Sud Milano. Conoscenza e gestione di un territorio agricolo. Provincia di Milano. Milano, Italy.

Biermann S., Rathke G.-W., Hülsbergen K.-J., Diepenbrock W. 1999. Energy recovery by crops in dependence on the input of mineral fertilizer. Research Report, Agrarökologisches Institut und Institut für Acker- und Pflanzenbau der Martin-Luther-Universität Halle-Wittenberg. EFMA Publication, http://www. efma.org/publications/index.asp; last checked on 20 November 2008.

Bockstaller C., Girardin P. 2003. Mode de calcul des indicateurs agri-environmentaux de la methode INDI$\mathrm{GO}^{\circledR}$. Version $1.61 \mathrm{du}$ logiciel. Unpublished INRA internal technical report.

Bockstaller C., Girardin P., van der Werf H.M.G. 1997. Use of agro-ecological indicators for the evaluation of farming systems. Eur. J. Agron., 7:261-270.

Bonzini S., Verro R., Otto S., Lazzaro L., Finizio A., Zanin G., Vighi M. 2006. Experimental validation of a geographical information systems-based procedure for predicting pesticide exposure in surface water. Environ. Sci. Technol., 40:7561-7569.

Borin M., Menini C., Sartori L. 1997. Effects of tillage systems on energy and carbon balance in north-eastern Italy. Soil Tillage Res., 40:209-226.
Caporali F., Mancinelli R., Campiglia E. 2003. Indicators of cropping system diversity in organic and conventional farms in central Italy. Int. J. Agric. Sust., 1:67-72.

Castoldi N. 2008. Environmental and economic assessment of agricultural systems at crop, field, farm, and regional scale. Application of agro-ecological and economic indicators in northern Italy. $\mathrm{PhD}$ Thesis. Univ. of Milano, Italy.

Castoldi N., Bechini L. 2006. Agro-ecological indicators of field-farming systems sustainability. I. Energy, landscape and soil management. Riv. Ital. Agrometeorol. / Ital. J. Agrometeorol., 1:19-31.

Castoldi N., Bechini L., Stein A. 2008. Evaluation of the spatial uncertainty of agro-ecological assessments at the regional scale: The phosphorus indicator in Northern Italy. Ecol. Indicators. In press. doi: 10. 1016/j.ecolind.2008.10.009.

Castoldi N., Bechini L., Steinberger J., Binder C.R. 2007a. Sustainability solution space using agro-ecological indicators at field level. In: Donatelli M., Hatfield J., Rizzoli A. (eds.): Int. Symposium on Methodologies on Integrated Analysis on Farm Production Systems, Book 2 Field-farm scale design and improvement. Proceedings $1^{\text {st }}$ Farming Systems Design, Catania, Italy, 10-12 September, 99-100.

Castoldi N., Finizio A., Bechini L. 2007b. Agro-ecological indicators of field-farming systems sustainability. II. Nutrients and pesticides. Riv. Ital. Agrometeorol. / Ital. J. Agrometeorol., 1:6-23.

Ceccon P., Coiutti C., Giovanardi R. 2002. Energy balance of four farming systems in North-Eastern Italy. Ital. J. Agron. / Riv. Agron., 6:73-83.

Day W. 2005. Engineering precision into variable biological systems. Ann. Appl. Biol., 146:155-162.

EEA (European Environmental Agency) 2005. Agriculture and environment in EU-15 - The IRENA indicator report, European Environmental Agency, Copenhagen, Denmark. [Online]. Available at: http://webpubs.eea.eu.int/content/irena/index.htm; last checked on 20 November 2008.

Fangueiro D., Pereira J., Coutinho J., Moreira N., Trindade H. 2008. NPK farm-gate nutrient balances in dairy farms from Northwest Portugal. Eur. J. Agron., 28:625-634.

Ferrero A., Vidotto F., Gennari M., Nègre M. 2001. Behavior of cinosulfuron in paddy surface waters, sediments, and ground water. J. Environ. Qual., 30:131-140.

Finizio A., Villa S., Vighi M. 2005. Predicting pesticide mixtures load in surface waters from a given crop. Agric. Ecosyst. Environ., 111:111-118.

Footprint Pesticide Properties Database 2008. [Online]. Available at: http://sitem.herts.ac.uk/aeru/footprint/ en/; last checked on 20 November 2008.

Garcia-Molina H., Ullman J.D., Widom J.D. 2002. Database Systems: The Complete Book. Prentice Hall, Upper Saddle River, NJ, USA.

Giupponi C. 2002. AGeNDA: a new tool for sustainable 
farm management, integrated in the agri-environmental policy of the EU. In: Proceedings of $8^{\text {th }}$ Joint Conference on Food, Agriculture and the Environment, 25-28 August 2002, Red Cedar Lake, Wisconsin, USA (working paper WP02-14).

Giupponi C., Carpani M. 2006. Recent developments in indicators and models for agri-environmental assessment. Ital. J. Agron. / Riv. Agron., 4:647-664.

Gras R., Benoit M., Deffontaines J.P., Duru M., Lafarge M., Langlet A., Osty P.L. 1989. Le fait technique en agronomie, Activité agricole, concepts et méthodes d'étude, Institut National de la Recherche Agronomique, L'Hamarttan, Paris, France.

Heyer W., Hülsbergen K.J., Wittman C., Papaja S., Christen O. 2003. Field related organisms as possible indicators for evaluation of land use intensity. Agric. Ecosyst. Environ., 98:453-461.

Marinari S., Mancinelli R., Campiglia E., Grego S. 2006. Chemical and biological indicators of soil quality in organic and conventional farming systems in Central Italy. Ecol. Indicators, 6:701-711.

Meul M., van Passel S., Nevens F., Dessein J., Rogge E., Mulier A., van Hauwermeiren A. 2008. MOTIFS: a monitoring tool for integrated farm sustainability. Agron. Sustain. Dev., 28:321-332.

Migliorini P., Vazzana C. 2007. Biodiversity indicators for sustainability evaluation of conventional and organic agro-ecosystems. Ital. J. Agron. / Riv. Agron., 2:105-110.

OECD (Organisation for Economic Co-operation and Development) 1999. Environmental Indicators for Agriculture, Concepts and framework, Vol. 1. OECD Proceedings. OECD Publication Service, Paris, France.

OECD (Organisation for Economic Co-operation and Development) 2001. Environmental Indicators for Agriculture, Methods and Results, Vol. 3. OECD Proceedings. OECD Publication Service, Paris, France.

OECD (Organisation for Economic Co-operation and Development) 2002. The development of agri-environmental indicators in the EU: the IRENA project, Statistic directorate. STD/NA/AGR(2002)16.
OECD (Organisation for Economic Co-operation and Development) 2005. Summary Report of the OECD Project on Pesticide Terrestrial Risk Indicators (TERI). ENV/JM/MONO(2005)11.

Padovani L., Trevisan M., Capri E. 2004. A calculation procedure to assess potential environmental risk of pesticides at the farm level. Ecol. Indicators, 4:111-123.

Parris K. 1998. Agricultural nutrient balances as agri-environmental indicators: an OECD perspective. Environ. Pollut., 102:219-225.

Regione Lombardia 2008. SIARL - Sistema Informativo Agricolo Regione Lombardia. [Online]. Available at http://www.agricoltura.regione.lombardia.it/sito/tmpl_action.asp? action $=$ sezione $\&$ Sezione $I d=220000000$ 0; last checked on 20 November 2008.

Richard G., Boizard H., Roger-Estrade J., Boiffin J., Guérif J. 1999. Field study of soil compaction due to traffic in northern France: pore space and morphological analysis of the compacted zones. Soil Tillage Res., 51:151-160.

Rosnoblet J., Girardin P., Weinzapflen E., Bockstaller C. 2006. Analysis of 15 years of agriculture sustainability evaluation methods. In: Fotyma M., Kaminska B. (eds.): European education and research in agronomy. Proceedings of $9^{\text {th }}$ ESA Congress, Warszawa, Poland, 4-7 September, 707-708.

Sacco D., Bassanino M., Grignani C. 2003. Developing a regional agronomic information system for estimating nutrient balances at a larger scale. Eur. J. Agron., 20:199-210.

Tomlin C.D.S. (ed.) 2003. The pesticide manual: a world compendium, thirteenth edition, British Crop Protection Enterprises, Farnham, United Kingdom.

Van Beek C.L., Brouwer L., Oenema O. 2003. The use of farmgate balances and soil surface balances as estimator for nitrogen leaching to surface waters. Nutr. Cycl. Agroecosys., 67:233-244.

Vereijken P. 1995. Designing and testing prototypes; progress reports of the research network on integrated and ecological arable farming systems for EU and associated countries (Concerted Action AIR 3 CT920755), Wageningen, The Netherlands. 